\title{
O pensamento ambiental de Al Gore
}

\author{
Igor Zanoni Constant Carneiro Leão*
}

Leone Rigamonti Girardi*

\begin{abstract}
RESUMO - Al Gore (1948) é militante do movimento ecológico desde sua juventude, tendo também estudado questões ligadas à família norte-americana, escrevendo diversos livros importantes sobre esses temas. Aqui apresentamos um registro de seu pensamento ambiental em três dos seus textos sobre o assunto, não apenas por sua eminente posição na política norteamericana mas por ligar de modo original a questão ambiental aos problemas políticos vividos recentemente pela sociedade e governo dos Estados Unidos.
\end{abstract}

Palavras-chave: Ecologia. Política internacional. Pensamento ambientalista.

Este texto é uma notícia sobre o pensamento ambiental de Albert (Al) Gore, vice-presidente dos Estados Unidos durante a presidência de Bill Clinton, diversas vezes membro da Câmara dos Deputados e senador norte-americano, empresário e autor de diversos livros sobre a cultura americana, destacando-se seu pensamento ambiental. Nesta última linha escreveu os best sellers A Terra em Balanço e Uma Verdade Inconveniente (também transformado em vídeo), além de incluir um importante capítulo sobre meio ambiente em seu último livro, O Ataque à Razão. Seu pensamento nesta área é importante não apenas pela relevância da condição política e empresarial do autor, ou da relevância do tema, mas especialmente pela lucidez e coragem com que ele é abordado.

A ideia de uma ameaça ambiental global foi apresentada a Al Gore quando ele ainda era estudante na década de 60 e, com o passar dos anos, ele passou a estudar seriamente o aquecimento da Terra e várias outras questões ambientais. Percebeu que no final da década de 70 o assunto despertava algum interesse em largo segmento da população, mas poucos estavam dispostos a pensar no caráter abrangente de uma solução necessária.

A queima e devastação das florestas tropicais, o acelerado ritmo de extinção de espécies, a contaminação do ar, da água e do solo, o aquecimento da Terra e a diminuição da camada de ozônio e outras tragédias ambientais já são amplamente reconhecidos como diferentes consequências do choque entre a civilização mundial e o sistema ecológico da Terra. Para Al Gore, que hoje é um ativista ecológico fervoroso, esse choque ocorre como consequência da explosão demográfica, "que hoje acrescenta à população o equivalente a uma China a cada dez anos", da *Doutor em economia pela Universidade Estadual de Campinas. É professor associado do Departamento de Economia da Universidade Federal do Paraná. Endereço eletrônico: igorzaleao@yahoo.com.br.

**Graduada em economia pela Universidade Federal do Paraná. Endereço eletrônico: leoyoukai@yahoo.com.br. 
revolução científica e tecnológica, que aumentou o poder do homem de manipular a natureza e sua capacidade de causar impacto sobre o mundo, e do modo de pensar sobre a relação com o meio-ambiente, "à medida que cedemos às fortes pressões para recusar a responsabilidade pelas consequências futuras de nossos atos atuais".

Em sua obra A Terra em Balanço, Ecologia e Espírito Humano, 1992, que é considerada por muitos a declaração mais abrangente sobre o meio ambiente já feita por um político importante, Al Gore faz um apelo pessoal onde todos os aspectos do problema são abordados e propõe possíveis soluções. Para isso, ele entrou em contato com muitos especialistas e foi capaz de viajar e assistir algumas das maneiras em que as decisões pobres por parte do governo e da indústria afetam negativamente o meio ambiente. Como afirma o autor:

Todos já tomamos conhecimento de experiências surpreendentes que nos advertem sobre o perigo que representa nossa agressão ao meio ambiente, seja a nova frequência de dias em que a temperatura ultrapassa 38 graus centígrados, seja a nova rapidez com que o sol queima nossa pele ou a frequência atual dos debates públicos sobre o que fazer com as crescentes montanhas de rejeitos. Por que não empreendemos esforços maciços para salvar o meio ambiente? (p. 30)

E também:

O aquecimento da terra representa uma ameaça. A concentração de dióxido de carbono e de outras moléculas que absorvem o calor aumentou em quase $25 \%$ desde a Segunda Grande Guerra, representando uma ameaça mundial à capacidade da Terra de regular a quantidade de calor solar retida na atmosfera. Essa elevação da temperatura ameaça seriamente o equilíbrio climático mundial que determina o padrão dos ventos e das chuvas, as temperaturas da superfície, as correntes marítimas e o nível dos mares. Esses elementos, por sua vez, determinam a distribuição da vida vegetal e animal na terra e no mar e tem grande influência na localização e nos padrões das sociedades humanas. (p. 33)

Toda a relação entre a humanidade e a Terra vem se transformando, porque a civilização de repente se tornou capaz de afetar o meio ambiente de todo o globo terrestre e não apenas de uma determinada área. Al Gore também trouxe a ideia de que "a crise ecológica é a manifestação exterior de uma crise interna de espírito", e de acordo com ele, a estrutura da civilização está se tornando extremamente complexa, mas, conforme aumenta essa complexidade, aumenta também a distância de nossas raízes e "tornou-se fácil demais encarar a Terra como um conjunto de recursos cujo valor intrínseco não é maior que sua utilidade no momento".

Primeiramente, Al Gore tem o objetivo de dissipar a noção de que os problemas ambientais não são suficientemente graves para exigir uma ação imediata, e, também deixa claro 
que quer que os Estados Unidos assumam a liderança nesta questão (criticou o governo Bush por não fazê-lo).

Declarou que todas as pesquisas de opinião pública que abordaram o tema ambiental constataram que os norte-americanos rejeitaram o argumento do governo Bush, de que devem escolher entre a manutenção de empregos e o meio-ambiente. Acreditam, ao contrário, que podem prosperar liderando a revolução ambiental e criando para o mercado mundial os novos produtos e tecnologias que fomentam o progresso econômico sem a destruição da natureza. De fato, muitos especialistas acreditam "que podemos criar milhões de novos empregos liderando a revolução ambiental e acelerando nossos esforços para fabricar e vender produtos e tecnologias adequados ao meio ambiente".

Ele também descreve algumas das maneiras pelas quais a economia clássica não conta para os custos reais de produtividade. Por exemplo, o desgaste de motosserras e tratores é um custo aceitável de fazer negócios, mas o desgaste das florestas é ignorado. Ele atribui essa situação à insistência em nos perceber como algo separado da natureza e imune aos seus problemas:

Ao distinguirmos entre o que é ainda incerto e o que é certo sobre a crise ambiental, é importante deixar claro que a natureza revela um padrão repetitivo de interdependência das várias partes do sistema ecológico. Podemos afirmar com grande segurança, que, se de alguma forma perturbarmos o equilíbrio ecológico da Terra, os reflexos se farão sentir em todo o sistema. Assim, embora uma determinada conduta possa parecer inofensiva na parte do meio ambiente que podemos observar, provavelmente não temos conhecimento suficiente dos efeitos do que estamos fazendo, para prever as consequências nas outras partes do sistema - exatamente porque todas as partes funcionam dentro de um delicado equilíbrio de interdependência. (p.56)

Nessa obra em especial, Al Gore sugere algumas ações principais como estabilizar a população mundial através de um programa de três pontos para aumentar a alfabetização, reduzir a mortalidade infantil e promover métodos de controle de natalidade; desenvolver tecnologias adequadas através de um ambiente estratégico (iniciativa que aborda os problemas da agricultura, florestal, energia, tecnologia de construção, redução e reciclagem de resíduos etc.); estabelecimento de novas regras da economia global; negociar novos acordos internacionais que são sensíveis às diferenças entre países desenvolvidos e subdesenvolvidos; e, educar os cidadãos do mundo para uma nova maneira de pensar sobre a relação da humanidade com a terra.

No documentário ambientalista Uma Verdade Inconveniente, 2006, vencedor do Oscar de melhor documentário em 2007, Al Gore mais uma vez salienta que o aquecimento global além de ser uma questão política e econômica, uma vez que está intrinsecamente ligada ao desenvol- 
vimento industrial, é o maior desafio global que teremos de enfrentar.

O filme mostra uma séria advertência para a humanidade sobre suas responsabilidades com as mudanças climáticas. As imagens, com intuito de impressionar e incomodar mostram as atuais alterações que o planeta Terra está experimentando, a evidência da irresponsabilidade dos políticos que se negam a reconhecer a urgência de tocar no assunto, e, o pouco tempo que resta para se evitar uma catástrofe.

No filme e nas suas palestras, Al Gore derruba com dados concretos grandes mitos existentes sobre o aquecimento global, como à realidade do efeito estufa, se as políticas ambientais afetam a economia dos países, e, que o aquecimento global faz parte de um ciclo natural da Terra. Ele confirma que muitos estudos científicos provam que o efeito estufa, e consequentemente o aquecimento global, é real e constitui uma séria ameaça para a vida na Terra; demonstra com modelos econômicos de autorizadas personalidades do mundo que as políticas públicas baseadas num planejamento ambiental estimulam as economias dos países ao invés de afetálas; e ainda, que o aquecimento global não é somente um ciclo natural da Terra, mas também o resultado de atividades humanas no campo e na indústria.

$\mathrm{Al}$ Gore apresenta que é concreto que quase todas as atividades industriais dependem do desmatamento e da desidratação do planeta. Além do corte das árvores para produzir madeira industrializada e carvão vegetal, a construção de hidroelétricas para gerar energia elétrica com as suas indispensáveis barragens é responsável pela inundação de enormes áreas emissoras de gases de efeito estufa, reduzindo a camada atmosférica e aumentando o nível térmico mundial. Também é concreto que algumas das consequências do desmatamento são a desertificação, as secas, as inundações e o incremento do número de furacões, tufões e outros tipos de tempestades de grande dimensão, e, o aquecimento atmosférico que derrete as calotas polares leva à dessalinização das águas oceânicas e a mudanças radicais nos ecossistemas e na capacidade imunológica de todos os seres vivos.

Em virtude deste cenário, $\mathrm{Al}$ Gore insiste em que "a solução para a crise climática global exige uma ação rápida, sábia e grande de nossa parte”. Na mensagem aos empresários, ele lembra que "se destruirmos o planeta não haverá economia que sobreviva", e, ataca a causa principal, que é a cultura dos países industrializados concentrada no consumo, na ganância, e na expansão dos negócios em níveis insustentáveis.

Al Gore propõe como solução para a crise climática um amplo programa conjunto liderado pelos Estados Unidos que denomina um novo Plano Marshall global, à semelhança do implantado na Europa no pós-Segunda Guerra. Este plano interviria fortemente sobre a tecnologia, as formas de produção industrial e agrícola em todo o mundo, combatendo ainda fenô- 
menos como a desertificação, o uso abusivo da água e o desmatamento das florestas tropicais, entre outros itens relevantes.

Todavia, em seu último livro, O Ataque à Razão, 2008, destinado a uma crítica do sistema político norte-americano durante o governo George Walker Bush, o tom do discurso ambiental se politiza também com muita força. O livro procura mostrar que a democracia norte-americana corre perigo por diversas razões, como a preeminência do Executivo sobre os outros poderes, a importância da mídia no processo de formação de opinião política, a mentira sistemática, o ataque ao indivíduo, a política bélica no Iraque e outros temas ligados a um desvirtuamento dos marcos fundamentais nos quais foi criada a república norte-americana, pelos chamados pais fundadores da nação, como Thomas Jefferson e James Madison, entre outros. Isto tem uma ligação profunda com a crise ambiental.

Para o autor, a razão deveria guiar o sistema político, mas tem sido substituída pela influência da riqueza e do poder, criando patologias como a dissimulação, o sigilo, a política do medo, a substituição do conhecimento e da lógica por poder bruto, o apelo a uma "cruzada", o que pode ser atestado em todo vigor nas políticas energéticas e ambientais. Ele pensa que os Estados Unidos deveriam empreender uma iniciativa estratégica de grande porte para solucionar a crise, que tem duas faces, do clima e da dependência de combustíveis fósseis.

Em primeiro lugar, o consumo americano mantém os preços mundiais do petróleo altos, assegurando um fluxo contínuo de petrodólares aos cofres de estados como o Irã, que tem demonstrado hostilidade aos interesses americanos, e a Arábia Saudita, onde somas vultosas aparentemente foram desviadas para treinar e dar apoio a terroristas.

As grandes nações produtoras buscam maximizar seus lucros com a exportação do óleo, mas também tentam manipular a vontade política norte-americana. Isto pode ser visto no fato de nos últimos trinta anos reduzirem preços sempre que o Ocidente chega perto de reconhecer a prudência do desenvolvimento de energia renovável própria.

Por outro lado, a dependência do óleo criou duas guerras no Golfo Pérsico, exigindo hoje substitutos sustentáveis do ponto de vista ambiental para os combustíveis fósseis e uma iniciativa de fato internacionalizada para estabilizar o Golfo Pérsico e reconstruir o Iraque.

Este dado se liga a críticas ao governo Bush:

Em 2007, enquanto o Iraque se desintegrava em meio à violência sectarista, o governo Bush redigia, com muito cuidado, documentos legais - enquanto os EUA ainda eram o poder de ocupação - que garantiam acesso preferencial aos enormes lucros esperados da produção das enormes reservas de petróleo do Iraque para a ExxonMobil, a Chevron, a BP e a Shell. (p. 176) 
Isto significa um terrível acordo para os iraquianos e os cidadãos da região, que foram totalmente excluídos do processo. Além disso, o comércio de mão única é destrutivo para o futuro econômico, o que exige invenção e produção de novas soluções para deter o aquecimento global dentro dos EUA e tornar mais recíprocas as vias do comércio internacional com o Golfo Pérsico e outros produtores de óleo.

$\mathrm{Al}$ Gore chama a atenção para o fato de que a maior parte das questões ambientais que as pessoas enfrentam tem natureza essencialmente local: poluição da água, poluição do ar e depósitos de lixo tóxico. Nas últimas décadas a consciência ambiental começou a se concentrar em uma nova classe de ameaças ambientais regionais, como a chuva ácida, especialmente no meio oeste e no noroeste americanos, e o esgotamento de depósitos subterrâneos de água doce em oito estados nas planícies centrais entre a bacia do rio Mississipi e as Montanhas Rochosas.

O governo Bush deixou de proteger o meio ambiente nessas três categorias e entregou o controle das políticas ambientais nas mãos de empresas que mais poluem e de outras com interesses particulares que vêm enfraquecendo ou dilacerando os padrões ambientais, isto pode ser visto na maneira como o governo Bush lida com o mercúrio, com a limpeza dos depósitos de lixo tóxico e com a mudança no gerenciamento dos parques nacionais americanos. Por outro lado, as pessoas são alvo de uma campanha enorme e muito bem organizada de desinformação, impulsionada pelo governo e fartamente financiada por empresas poluidoras. Essas empresas se juntam a ideólogos de direita fingindo que existe discordância significativa entre os cientistas em áreas nas quais há um amplo consenso básico. Todos esses exemplos fazem crer que o governo Bush-Cheney é de total propriedade das empresas de carvão, petróleo, fornecimento de serviços públicos e mineração.

A relação fundamental entre a espécie humana e o planeta não se mede apenas pelo dióxido de carbono lançado na atmosfera, mas na destruição de florestas na superfície do planeta, na destruição de áreas de pesca oceânica e pela ameaça iminente da extinção de praticamente todas as espécies oceânicas importantes em menos de meio século, se as taxas de exploração forem mantidas. Também se mede pela destruição da camada de ozônio estratosférica, que há uma ligação entre o esgotamento do ozônio estratosférico e o aquecimento global, pois em ambos os casos a substância química que causa o problema é invisível e produz suas consequências ameaçadoras em dimensão global.

Para o autor, as ameaças ambientais estratégicas são similares aos conflitos mundiais, globais ou militares, no sentido de necessitarem de uma mobilização global completa como a única maneira de garantir que o resultado será o futuro positivo para a civilização humana.

Essas ameaças vão desde o aumento do poder de destruição dos furacões aos incêndios 
florestais em verões com temperaturas recordes em várias regiões do globo. O acontecimento mais notável recente foi o furacão Katrina, mas também precisamos olhar para fenômenos como a liberação de emissões de metano e carbono da tundra na Sibéria que está começando a descongelar.

Al Gore mostra que fenômenos como o Katrina ou o ataque iminente da Al-Qaeda em 11 de setembro foram previstos sem reação do governo Bush. Houve uma imobilidade do governo norte-americano inexplicável, colocando em risco cidadãos americanos.

O texto de $\mathrm{Al}$ Gore é interessante porque as nações desenvolvidas sempre trataram a natureza e o ser humano dentro da base cultural do liberalismo econômico como um fator de produção e bens fundamentais como a terra, o ar, a água, as florestas e a vida nunca tiveram valor ecológico. O capitalismo se expandiu exportando um desenvolvimento que degradou e esgotou recursos naturais, destruiu relações sociais sem levar em conta a cultura e a dinâmica local dos países subdesenvolvidos. Como resultado, aumentaram as desigualdades sociais, a pobreza, as diferenças de renda entre os países, a degradação dos ecossistemas rurais e urbanos, caracterizando um fracasso das políticas desenvolvimentistas sem preocupação com a sustentabilidade ambiental.

$\mathrm{Na}$ atualidade, percebe-se claramente que o planeta está enfermo e que órgãos como as Nações Unidas se movem não só para assegurar a paz mundial e a cooperação internacional, mas também para resolver de forma pacífica problemas de ordem econômica, social, cultural e humanitária, chegando hoje a procurar uma forma de sustentabilidade do desenvolvimento cercada de boa vontade política. Entretanto, as grandes potências pouco fizeram para sair do campo puramente econômico do desenvolvimento, não levando em conta a dívida ecológica que este trouxe para todos os países.

$\mathrm{O}$ interesse dos textos de $\mathrm{Al}$ Gore é retomar fortemente essas preocupações, dando um lugar ativo aos Estados Unidos para enfrentar as ameaças climáticas globais. Além disso, apesar de ser figura de proa no estabilishment norte-americano, liga essas ameaças a uma inércia política do governo Bush que atinge também todo o arcabouço fundamental da democracia naquele país. Nesse sentido só se pode esperar que o governo Barak Obama possa se mover de forma coerente com os fundamentos da constituição norte-americana, e com o sentido de empreender no mundo ações de paz, de proteção humana e ajuda efetiva aos povos no interior do complexo tecido político e econômico do planeta. 


\section{REFERÊNCIAS}

GORE, A. Terra em Balanço. São Paulo: Editora Augustus, 1993.

. Uma Verdade Inconveniente: o que Devemos Saber e Fazer Sobre o Aquecimento Global. São Paulo: Manole, 2007.

O Ataque à Razão. São Paulo: Manole, 2008. 